\title{
Cell wall's mesoscale organization in Deinococcus radiodurans
}

\author{
Authors: Domenica Farci ${ }^{1,2^{*}}$, Patrycja Haniewicz and Dario Piano
}

\section{Affiliations:}

1

Department of Plant Physiology, Warsaw University of Life Sciences - SGGW, Warsaw, 02-776, Poland;

2

Department of Chemistry, Umeå University, Linnaeus väg 6, 90736, Umeå, Sweden;

3

Laboratory of Plant Physiology and Photobiology, Department of Life and Environmental Sciences, Università degli Studi di Cagliari, Viale S. Ignazio da Laconi 13, 09123 Cagliari, Italy. *Corresponding author.

\section{Summary}

S-layers are highly-ordered coats of proteins localized on the cell surface of many bacterial species. In these structures, one or more proteins form elementary units that self-assemble into a crystalline monolayer tiling the entire cell surface. Here, the cell wall of the radiation-resistant bacterium Deinococcus radiodurans was studied by high-resolution cryo-electron microscopy finding the crystalline regularity of the S-layer clearly extended into the layers below. The cell wall appears to be highly packed and resulting from a three-dimensional crystalline distribution of proteins complexes organized in close continuity but allowing different degrees of voidness along the cell wall thickness. These insights grade S-layers to mesoscale hubs behaving as structural and functional architraves essential for the entire cell body.

\section{Keywords}

Deinococcus radiodurans, cryo-electron crystallography, cryo-electron tomography, S-layer, cell wall, Type IV-Piliation System, SDBC

\section{Introduction}

Surface layers (S-layers) are ordered repetitions of proteinaceous units that tile the cell body of many prokaryotes [Sleytr and Glauert, 1975; Bahl et al., 1997; Messner et al., 1997]. The periodical unit of S-layers consists of one or more proteins that, in some species, are further 
organized in multi-protein complexes [Fagan and Fairweather 2014; Farci et al., 2018a; Farci et al., 2021]. These coating structures are common in Bacteria and Archaea and have essential roles in providing cell rigidity, shape, adhesion, and resistance to extreme conditions [Beveridge et al., 1997; Pavkov-Keller et al., 2011; Farci et al., 2018b; Kumar et al., 2021]. Despite of their relevance in the cell wall, detailed molecular and in situ studies on S-layers are still limited leading to a distinct degree of uncertainty about their roles and functions. However, the self-assembly properties of S-layer proteins [Pum et al., 2013], and the levels of energy consumption implied for their high expression and displacement, self-stand for a deep functionalization and specialization of these structures. Being the forefront of the cell to the environment, S-layers represent one of the cell's compartments more exposed to selective pressure and, in extremophiles, cope with harsh conditions that are typically deviating from the canonical ones sustaining life [Farci et al., 2016]. This fact ranks S-layers as one of the cell's regions most subjected to specialization in bacteria. One of the model organisms for S-layer studies is the radiation-resistant bacterium Deinococcus radiodurans. Its S-layer has been investigated by several techniques and its surface structure and porous organization were previously described at low resolution [Baumeister et al., 1982; Baumeister et al., 1986; Müller et al., 1996; Lister and Pinhero, 2001]. In the last decade, the research done on this S-layer provided important details on its organization, composition, and properties, eventually resulting in an overall vision with features somehow overlooked since then. In particular, this S-layer was found to be composed by several proteins further organized into different protein complexes [Farci et al., 2014; Farci et al., 2015]. Taken together, these studies provided multiple and indirect evidence suggesting the absence of a distinct separation between the S-layer and the underlying membranes [Rothfuss et al., 2006; Farci et al., 2014; Yu et al., 2017; Farci et al., 2020; Farci et al., 2021]. To shed a light on the S-layer extension into and interaction with the rest of the cell wall, here we explore the in-situ 3D organization of this S-layer. Cell wall patches were characterized by mean of 3D cryo-electron crystallography (cryo-EC) crossreferenced by cryo-electron tomography (cryo-ET) and subsequent subtomogram average. Results describe an unexpectedly sophisticated crystalline regularity, with a 3D organization consisting of an ordered juxtaposition of three multi-protein complexes recently observed in their 2D organization [Farci et al., 2021] and here shown to extend into the entire cell-wall thickness. The periodical organization of these complexes results in a highly packed cell-wall structure that, despite the close continuity of its components, still allows for different degrees of voidness along the cell-wall thickness. While one of these complexes appears to be exclusive of the cell-wall 
surface, involving the S-layer and the outer membrane, the other two complexes, a Type IV-like Piliation system (T4P-like) and the S-layer Deinoxanthin Binding Complex (SDBC), that were previously described as channels [Gold et al., 2015; Farci et al., 2021], here are shown to span the layers below representing the main in/out system of sieving in the cell. Such an organization force the cell wall trafficking through the two main available ways, the T4P-like and the SDBC, opening for a centralized and discrete functional displacement along and across the cell wall. The presented findings candidate S-layers as fundamental structures that "drive" the cell wall organization from the level of cell body down to molecular level according to a mesoscale model where active and central functions are implied.

\section{Results}

An extended crystalline organization characterizes the cell wall of Deinococcus radiodurans Given the general properties of radiation-resistance and the abilities of its S-layer to shield the UV radiation [Daly, 2009; Farci et al., 2016], a direct radiation damage in D. radiodurans is likely to be damped by the robustness of its structures. This property makes $D$. radiodurans an optimal candidate for studies of the cell wall by electron microscopy. Taking advantage of the S-layer crystallinity, the diffraction properties of the cell wall were used as a discriminant for selecting the best patches to be subjected to cryo-EC, cryo-ET, and subtomogram average. Accordingly, only integral cell wall patches showing both membranes and sharp diffraction patterns with reflections beyond $2.8 \AA$ were selected (Fig. 1). Diffraction analyses by independent processing and subsequent merging of 73 micrographs at different tilting angles of six different patches led to a 3D electron density map that allowed an indirect visualization in situ of the crystalline regions in the cell wall (Fig. 2; EMDB-14097). The phase residuals post-processing indicated information up to $4 \AA$ (Table 1) and, interestingly, the reflections carried information not only of the S-layer, well known for its $\sim 10$ Å thick crystalline packing [Baumeister et al. 1986], but also of the underlying space, providing striking evidence of a crystallinity extended for $\sim 200 \AA$ into the cell wall (Fig. 2 and Sup. Movie 1).

Three different protein complexes account for the three-dimensional cell wall crystalline packing 
A consistent volume of the cell wall appears to be occupied by three complexes. The larger complex shows an overall shape that resembles the one of many secretion systems and fits well with the 1.1 MDa complex, called Type IV Piliation-like system (T4P-like; Fig. 3a). This complex was found to be abundant in these cell walls and to have as main component the protein DR_0774, a pilin Q commonly constituting the head region and interacting with the outer membrane in many secretion systems [Farci et al., 2014]. With a height of $175 \AA$ (Fig. 3a), a main hexagonal head with a side of $85 \AA$ and a diameter of $150 \AA$ (Fig. 3b, d, and g), the T4P-like complex spans the Slayer, the outer membrane, and the periplasm reaching the inner membrane (Fig. 3a and f). On the top of the head, a multiple-spikes crown emerges and expands for $20 \AA$ defining the pore region (Fig. 3a). According to the p6 symmetry of this S-layer, each T4P-like is surrounded by 6 copies of a smaller complex, the S-layer Deinoxanthin Binding Complex (SDBC), extensively described and characteristic of these cell walls [Farci et al., 2016; Farci et al., 2019; Farci et al., 2020; Farci et al., 2021]. Recognizable by its triangular shape (with a side length of $90 \AA$ and a thickness of $\sim 30 \AA$ ), this $\sim 0.9$ MDa complex has the main body embedded in the outer membrane and is located inside of a "cell-wall case" (Fig. 3b, c, d, and f), as already observed in middle-high resolution studies on the surface of this cell wall [Farci et al., 2021]. Differently from what was observed before in purified SDBC samples [Farci et al., 2021], here from the main body depart three harms facing the external environment and other three toward the periplasmic side (Fig. 3c and f). Finally, a third dihedral complex of unknown identity, characterized by a typical C2 symmetry with a side of $70 \AA$, a width of $45 \AA$ (Fig. 3b, d, and g), and a height of $60 \AA$ (Fig. 3a and f), was found to be localized in the S-layer and to span the underlying outer membrane (Fig. 3a). By exclusion we hypothesize that this third complex could be the DR_2508 protein, which is known as HPI (Hexagonally Packed Intermediate) [Baumeister et al., 1982; Baumeister et al., 1986; Rothfuss et al., 2006] and is the only known protein of this S-layer for which a precise localization is still missing. These three individual units, the T4P-like, the SDBC, and the dihedral complex here represented in orange, pink, and yellow, respectively, were extracted from the map providing a better view of their features and relative localization (Fig. 3f, g, and h; Sup. Movie 1).

As a preliminary cross-check of these observations, a mild solubilization of the cell wall sample and its subsequent fractionation by anionic exchange chromatography confirmed the dominance of these three protein complexes (Fig. 4a), as eventually shown by negative stained electron microscopy (Fig. 4b, c, and d). 

repetition of channels confirming the cryo-EC analysis

Cryo-ET and subtomogram average on the same data sets allowed an in-situ direct analysis of intact cell wall fragments (Fig. 5; EMDB-14095). At tomographic level, raw movies' slices (Fig. 5) and reconstructions (Sup. Movie 2) showed a repetition of proteinaceous units as top and side views. Overall, these analyses confirmed the organization described by cryo-EC, in particular showing a regular isoporous surface (interpore distance of $195 \AA$ vs $190 \AA$ measured by 3D cryoEC) with each pore corresponding to a T4P-like complex spanning the whole cell-wall layers (Fig. 5, upper-middle and upper-right insets, respectively), hence granting for an in situ direct visualization of the $3 \mathrm{D}$ regularity. A subsequent p6 symmetrization centred in the pore region allowed to better resolve the T4P-like complex ( $8 \AA$ best resolution; Fig. 6, Sup. Fig. 1, and Sup. Fig. 2; EMDB-14096) and compare it with the T4P-like structure extracted from the 3D cryo-EC map (Fig. 6). The subtomogram shows a clear dominance of the T4P-like occupancy (Sup. Fig. 2) with each complex having a side of $85 \AA$, a diameter of $\sim 150 \AA$, and a total height of $\sim 260 \AA$ (Fig. 6). Included in this structure are also non-crystalline regions that are missing in the model obtained in the 3D diffraction data $(\sim 20 \AA)$, and a $70 \AA$ height conical extension in the bottom part of the complex involving the inner membrane and the neighbouring cytoplasmic region (Fig. 6, Sup. Fig. symmetry at different levels confirming the consistency of the two independent analyses (Fig. 6, left and right boxes).

Finally, this analysis also allowed to measure the thickness of the entire cell wall and its regions. The whole thickness was fund to be of $299.5 \pm 2.8 \AA$ with a periplasm $\sim 99.3 \pm 12.2 \AA$ thick interacting to each other for $\sim 98.9 \pm 9.4 \AA$, and below by a "floor" consisting of an inner membrane $\sim 69.8 \pm 5.4 \AA$ thick (Sup. Fig. 3).

\section{Discussion}

We provide here the supramolecular description of the cell wall in the radiation-resistant bacterium D. radiodurans. The natural capability of this organism in withstanding high doses of radiations and the known crystalline properties of its S-layer were advantageous to perform a detailed 
characterization of the cell wall. The intrinsic properties of radiation resistance most likely delayed the electron damage of the samples resulting in a well-preserved overall structure and allowing a middle resolution characterization by 3D cryo-EC (Fig. 1 and 2) cross-referenced by cryo-ET (Fig. $5)$.

We demonstrate that the well-known S-layers' order in this specific case is ascribable to three multi-protein complexes (Fig. 3). The most astonishing and remarkable result is that the S-layer regularity pervades the underlying membranes, imposing a defined order to the cell wall (Fig. 3). The intricate structure resulting from a regular juxtaposition of protein complexes is expected to serve as an extended molecular sieving machine. This observation is unequivocally supported by its constituents, the T4P-like and the SDBC, already known for their gating properties [Gold et al. 2015; Farci et al. 2021]. Accordingly, through this organization the trafficking across the cell wall has the potential to be finely regulated by the discrete distribution of its components. This complex simplicity, consisting of two types of gates isotropically distributed on the whole cell-wall surface, allows to equalized the movements in/out of the cell with respect to the surrounding environment. The observation of this regularity appeared first by the diffraction properties of the cell-wall patches and after was confirmed by the 3D structural analyses (Figs. 1 and 2).

Taken together the present findings suggest the S-layer and the underlying membranes to occur according to a clear mesoscale organization. In fact, as a consequence of this cell-wall topology, a continuous proteinaceous system can be envisaged from the range of individual cells down to the one of molecular identities [Goodsell et al., 2020]. In such an organization, the crystalline unit cell represents a discrete structural unit, the repetition of which results in the association of 6 SDBC and 6 dihedral complexes for each T4P-like (Fig. 3). According to this spatial displacement and to the self-assembling properties of S-layer proteins [Pum et al., 2013], these three building blocks are expected to self-organize forming a large functional structure with several hierarchic levels, a characteristic feature of a mesoscale organization [Goodsell et al., 2020]. If on one hand this structural continuity provides extended compactness and statical isotropy at different levels, on the other hand by this structure the bacterium has an isotropic interaction with the surrounding environment by reaching an equally distributed exchange potential. Considering the well-known role of secretion systems and porins, such as the T4P-like [Gold et al. 2015; Craig et al., 2019] and the SDCB [Achouak et al., 2001; Vergalli et al., 2020; Farci et al. 2021], in exchanging across the cell wall, this property is relevant not only for the dynamics associated with the trafficking across, but also with the specific pool of functions that might specialize a given S-layer. 
Notably, while the cell wall compactness appears to be clearly an intrinsic property due to its organization, the data here presented show a significant free space with limited hindrances (Fig. $3 \mathrm{a}$ and $\mathrm{f}$ ). This is particularly true for the periplasm where, trafficking processes and molecular machineries not involved in the paracrystalline organization, need to have enough space for the functional activities related to cell maintenance and homeostasis (e.g., osmotic and energetic balance).

At this stage, it is not given to know how much this organization is common among different Slayers. Considering that similar symmetries and surface organizations are also associated to other type. These findings provide a new breath for studying S-layers and understanding their active roles in the physiology of the bacterial cell, flowing new information into the stimulating debate

\section{Materials and Methods}

\section{Cell culturing}

Deinococcus radiodurans cultures (strain R1; ATCC 13939) were cultivated in Tryptone Glucose Yeast extract broth (TGY) at $30^{\circ} \mathrm{C}$ for $24 \mathrm{~h}$, as describe by Murray [1992].

\section{Cell walls isolation and chromatography}

Cell walls were isolated at $4^{\circ} \mathrm{C}$ in dim light as describe in Farci et al., [2021]. Briefly, after harvesting by centrifugation $\left(5000 \mathrm{~g}, 10 \mathrm{~min}, 4^{\circ} \mathrm{C}\right)$, cells were resuspended in a $50 \mathrm{mM}$ sodium phosphate buffer at pH 7.8 (buffer A) supplemented with DNase I (100 U, DNase I recombinant, RNase-free Roche), and disrupted using a French Pressure Cell (3 cycles at 1100 psi). The sample was centrifuged twice $\left(2000 \mathrm{~g}, 10 \mathrm{~min}, 4^{\circ} \mathrm{C}\right)$ to remove the debris, then the supernatant was centrifuged to collect cell wall fragments $\left(48000 \mathrm{~g}, 10 \mathrm{~min}, 4^{\circ} \mathrm{C}\right)$. The final pellet was resuspended in buffer $\mathrm{A}$, digested with $100 \mu \mathrm{g} / \mathrm{mL}$ lyzozyme $\left(8 \mathrm{~h}, 30^{\circ} \mathrm{C}\right.$, under shaking at $\left.800 \mathrm{rpm}\right)$ to remove surface polysaccharides. Digested cell wall fragments were centrifuged (48000 g, $10 \mathrm{~min}, 4^{\circ} \mathrm{C}$ ), and washed three times with buffer A by a serial sequence of centrifugation/resuspension steps. Final samples were used for the cryo-electron crystallography and tomography. 
Anionic exchange chromatography was performed according to Farci et al., [2021]. Briefly, cell walls fragments were resuspended $\left(3-5 \mathrm{mg} / \mathrm{mL}\right.$ total proteins) and solubilised for $30^{\prime}$ at room temperature with a final concentration of $1.1 \%$ of $n$-dodecyl- $\beta$-D-maltoside ( $\beta$-DDM). After solubilization and centrifugation $\left(48000 \mathrm{~g}, 10 \mathrm{~min}, 4^{\circ} \mathrm{C}\right)$, the supernatant was subjected to anionexchange chromatography (Hi-load HP column, Amersham). After 5 column volumes of washing with buffer B (50 mM sodium phosphate, $\mathrm{pH} 7.4 ; 0.05 \%(\mathrm{w} / \mathrm{v}) \beta-\mathrm{DDM})$ at a flow rate of 0.5 $\mathrm{mL} / \mathrm{min}$, the elution was done with a linear gradient of $0-2.5 \mathrm{M} \mathrm{NaCl}$ in buffer $\mathrm{C}$ ( $50 \mathrm{mM}$ sodium phosphate, $\mathrm{pH} 7.4 ; 2.5 \mathrm{M} \mathrm{NaCl} ; 0.05 \%$ (w/v) $\beta$-DDM). All chromatography columns were subjected to the ReGenFix procedure (https:/www. regenfix.eu/) for regeneration and calibration prior use.

\section{Electron Microscopy}

Cryo-electron microscopy

The grid preparation and data acquisition were done at CEITEC, Brno, Czech Republic. Quantifoil plunge-freezing machine (Mark IV, ThermoFisher) at room temperature (blot force 2, blotting time $2 \mathrm{~s}, 100 \%$ humidity), and placed in autogrid (FEI, Eindhoven, Netherlands) prior image acquisition. Grids were transferred to a Titan-Krios TEM (ThermoFisher) operating at $300 \mathrm{kV}$ and equipped with a Cs-corrector (cs $2.7 \mathrm{~mm}$ ), a Quantum GIF energy filter (slit width set to 20eV), and a post-GIF K2 camera (Gatan) at a magnification corresponding to a pixel size of $2.28 \AA / \mathrm{px}$ $(\sim 21000 x)$. A dose-symmetric scheme ( $3^{\circ}$ increment, range $\left.\pm 60^{\circ}\right)$ was used for tomography acquisition by SerialEM software [Mastronarde, 2005]. The defocus was set to vary between $2 \mu \mathrm{m}$ and $5 \mu \mathrm{m}$.

Samples were negatively stained on glow-discharged copper grids (EMS200-Cu) covered with a 20 -nm carbon film. The purified complexes were applied at the grid in a volume of $3 \mu \mathrm{L}$ and the excess of sample was removed after $1 \mathrm{~min}$ by capillarity through a delicate touching of the grid bar with a filter paper (Whatman No. 1) for $2 \mathrm{sec}$. The grids were then stained for 1 min with $5 \mu \mathrm{L}$ of 2\% UranyLess TEM staining solution (Micro to Nano) and the excess of staining was removed by capillarity as in the previous step. Micrographs were acquired with a Tecnai F20 microscope (ThermoFisher Scientific) operating at $200 \mathrm{kV}$, with a FEI Eagle 4K CCD camera, at magnification of $53000 \mathrm{x}$. 


\section{Cryo-Electron Crystallography processing}

We collected 42 tomograms in movie mode (each tilting angle has a movie of 8 frames) for which $\mathrm{CTF}$ and ice quality was inspected. A total of 40 tomograms were selected for further processing. CTFs and resolution were estimated by CTFFIND3 [Mindell and Grigorieff, 2003]. For cryoelectron crystallography, 8-frames movies were drift corrected using MotionCor2 [Zheng et al., 2017] on the Focus package [Biyani et al., 2017]. Micrographs, at different tilting angles (see Table 1 for tilt angle distribution) and from the 6 best-diffracting tomograms, were processed on the same package but this time in $2 \mathrm{D}$ crystallography mode according to the latest implementations of the $2 d x$ package [Gipson et al., 2007]. By this procedure, it was obtained a complete set of information for each micrograph (defocus, tilt geometry, lattice, phase origin) and used to build a 2D projection map. Finally, data from the 73 best images were merged to obtain the final projection map by using the merge suite from Focus in 3D crystallography mode. The 3D model's visualization and the fittings were done using the Chimera software [Pettersen et al., 2004].

\section{Cryo-electron tomography and subtomogram average processing}

Tomograms were processed by the etomo software [Mastronarde, 2005]. Gold particles were used as fiducial markers and only tomograms with minimal alignment errors were selected for the final reconstruction [Mastronarde, 2005]. For sub/tomogram averaging on 3D reconstructions, subtomograms boxed with a size of $300 \times 300 \times 300$ voxels were manually selected and extracted. Subtomogram alignment and averaging with missing-wedge compensation was performed with the PEET software [Cope et al., 2011; Heumann et al., 2011] as following. Sub-tomograms were initially rotationally aligned assuming that translational shifts of sub-tomograms were approximately correct. Eulerian angles were determined by systematic search over some specified range of values with the range and the coarseness of the search being reduced in successive iterations of the search [Bostina et al. 2007]. Absolute values of cross-correlation were used for alignment potentially helping to prevent noise by reinforcing to match features in the reference [Cope et al., 2011; Heumann et al., 2011]. Finally, p6 symmetrization was performed using the scripts available for PEET. Isosurface visualization was accomplished using the Chimera software [Pettersen et al., 2004]. 


\section{Data and code availability}

The final 3D volumes and other relevant information about data acquisition and processing have been deposited in the Electron Microscopy Data Bank, EMD-14095, EMDB-14096; EMDB14097. All data will be released upon publication. This paper does not report original code. Any additional information required to reanalyze the data reported in this paper is available from the lead contact upon request.

\section{QUANTIFICATION AND STATISTICAL ANALYSIS}

Membrane isolation for data analyses was performed on more than 20 independent preparations. Micrographs, tomograms, and maps are representative of at least three independent replicates. Electron crystallographic image statistics and main images parameters are indicated on Table 1. All attempts to reproduce the results here presented were successful.

\section{Acknowledgments}

This work was supported by the National Science Center (Poland) with the Sonata BIS 7 Program (2017) Grant PRO-2017/26/E/NZ1/00344 and the Harmonia 10 Program (2018) Grant PRO2018/30/M/NZ1/00284 (both to D.P., D.F., and P.H.). We acknowledge the Cryo-electron microscopy and tomography core facility CEITEC MU of CIISB, Instruct-CZ Centre supported by MEYS CR (LM2018127). DF kindly thanks Dr. J.M. Heumann (University of Colorado Boulder) for the support with the subtomogram averaging processing using PEET.

\section{Author contribution}

Conceptualization: DP, DF. Investigation: DP, DF, PH. Visualization: DP, DF. Funding acquisition: DP. Project administration: DP, DF, PH. Supervision: DP. Writing - original draft: DP, DF, PH.

\section{Competing interest}

The authors declare no competing interest.

\section{Inclusion and Diversity}

While citing references scientifically relevant for this work, we actively worked to promote gender balance in our reference list. The author list of this paper includes contributors from the location 
where the research was conducted who participated in the data collection, design, analysis, and/or interpretation of the work.

\section{Figure legends}

Figure 1: Continuous regularity of isolated cell wall patches. Micrographs of cell wall patches let glimpse a patterned regularity resulting from a crystalline organization. The crystalline nature of the sample can be visualized by electron diffraction with a pattern of diffraction spots beyond $2.8 \AA$ resolution (inset). The scale bar indicates $500 \AA$.

Figure 2: Projection structures of the crystalline cell wall fraction. Map at $4 \AA$ with imposed p6 symmetry (EMDB-14097) visualized on the top view (a), bottom view (b) and side views (c and $\mathrm{d}$ ). The map clearly shows the main structural constituents organized in individual units. In the side views the thickness reaches $\sim 200 \AA$. The scale bar indicates $100 \AA$.

Figure 3: Projection structure with assigned densities. The specific occupancies for each complex are shown as side views at two sliced levels allowing to visualize the T4P-like in orange and the dihedral complex in yellow (a), and the SDBC in pink (c). For a better visualization slices at the top view level (b), at the outer membrane level (d), and at the bottom level (e) of the map are shown. Colored complexes represent the extracted densities from the original map. Side (f), top $(\mathrm{g})$, and bottom $(\mathrm{h})$ views of the extracted complexes and their relative position are also shown. The scale bar indicates $100 \AA$.

Figure 4: Chromatographic separation of the three cell wall complexes. The cell wall patches were mild solubilized and subsequently subjected to Anionic Exchange Chromatography (a) resolving in three main protein complexes: the T4P-like complex (b), the SDBC (c), and the dihedral complex (d). The scale bar indicates $500 \AA$.

Figure 5: Tomography and related subtomogram average analysis. a) Slice of a raw tomographic movie and FFT diffraction (upper-left inset) on a cell wall patch. A scale bar of 500 $\AA$ is shown. In the inset, it is shown a typical subtomogram average of cell wall patch (EMDB- 
14095) from the top view (upper-centered inset) and side view (upper-right inset). No symmetry was imposed. The scale bar indicates $50 \AA$.

Figure 6: Features comparison between tomographic and crystallographic T4P-like. The main dimensions of the T4P-like complex obtained by 3D electron diffraction (center left; EMDB14097) and by subtomogram average (center right; EMDB-14096) are compared. The left and right boxes show comparable images of the slice through at equivalent levels, from top to bottom, for the T4P-like complex obtained by cryo-EC (left box) and by cryo-ET subtomogram average (right box). Both maps were obtained by computing with imposed a p6 symmetry. Scale bars indicates $50 \AA \AA$.

Table 1: Electron crystallographic parameters and data.

\begin{tabular}{|c|c|c|}
\hline Plane group symmetry & \multicolumn{2}{|l|}{ p6 } \\
\hline Unit cell dimensions & \multicolumn{2}{|c|}{$\begin{array}{l}\mathrm{a}(\AA)=190 ; \mathrm{b}(\AA)=190 ; \mathrm{c}(\AA)=200 \\
\gamma\left({ }^{\circ}\right)=120\end{array}$} \\
\hline Number of images & \multicolumn{2}{|c|}{$\begin{array}{l}73 \\
\text { with tilt angle distribution: }\left[5\left(0^{\circ}\right) ; 6\left(+3^{\circ}\right) ; 3\left(-3^{\circ}\right) ; 4\left(+6^{\circ}\right) ; 5\left(-6^{\circ}\right) \text {; }\right. \\
4\left(+9^{\circ}\right) ; 4\left(-9^{\circ}\right) ; 4\left(+12^{\circ}\right) ; 4\left(-12^{\circ}\right) ; 2\left(+15^{\circ}\right) ; 1\left(-15^{\circ}\right) ; 2\left(+18^{\circ}\right) ; 2\left(-18^{\circ}\right) \text {; } \\
2\left(+21^{\circ}\right) ; 2\left(-21^{\circ}\right) ; 2\left(+24^{\circ}\right) ; 3\left(-24^{\circ}\right) ; 2\left(+27^{\circ}\right) ; 2\left(-27^{\circ}\right) ; 2\left(+30^{\circ}\right) ; 2(- \\
\left.30^{\circ}\right) ; 1\left(+33^{\circ}\right) ; 1\left(-36^{\circ}\right) ; 2\left(+39^{\circ}\right) ; 1\left(-39^{\circ}\right) ; 1\left(+42^{\circ}\right) ; 1\left(-42^{\circ}\right) ; 2\left(+45^{\circ}\right) \text {; } \\
\left.1\left(-45^{\circ}\right)\right]\end{array}$} \\
\hline Defocus range $(\AA)$ & \multicolumn{2}{|c|}{$39500-123738$} \\
\hline Magnification & \multicolumn{2}{|l|}{$21930 x$} \\
\hline Resolution in-plane $(\AA)$ & \multicolumn{2}{|l|}{4} \\
\hline Resolution in-z $(\AA)$ & \multicolumn{2}{|l|}{10} \\
\hline Number of observed unique reflections & \multicolumn{2}{|l|}{49905} \\
\hline Number of possible unique reflections & \multicolumn{2}{|l|}{25075} \\
\hline Overall phase error for 1000 spots $\left({ }^{\circ}\right)$ & \multicolumn{2}{|l|}{42,7} \\
\hline Resolution $(\AA)$ & Unique reflections $\left(\mathbf{N}^{\circ}\right)^{*}$ & Phase residual $\left({ }^{\circ}\right)^{* *}$ \\
\hline 12.7 & 102 & 24.9 \\
\hline 8.9 & 104 & 41.2 \\
\hline 7.3 & 101 & 41.4 \\
\hline 6.3 & 102 & 41.3 \\
\hline 5.7 & 104 & 47.9 \\
\hline 5.2 & 99 & 43.9 \\
\hline 4.8 & 104 & 47.1 \\
\hline 4.5 & 103 & 45.8 \\
\hline 4.2 & 96 & 52.3 \\
\hline 4.0 & 85 & 41.1 \\
\hline
\end{tabular}

* With $1 \leq \mathrm{IQ} \leq 6$ to $4.0 \AA$

**Amplitude-weighted, vectorial averaged phase residuals that shows the phase deviation from theoretical $0^{\circ} / 180^{\circ}\left(4^{\circ}\right.$ is random). 
Supplementary Figure 1: Tomographic parameters and resolution data. In the image is reported the Fourier Shell Correlation (FSC) for the symmetrized subtomogram average; the dashed-red line represents the spatial frequency with cutoff at 0.5 (Nyquist frequency - gold standard). The inset table reports the CTF parameters. Related to Figure 6.

Supplementary Figure 3: Cell wall layering and membranes localization. On the left is shown the tomographic reconstruction of a patch. The S-layer/outer membrane system (SL/OM) and the inner membranes (IM, black arrows) are highlighted with black arrows. The scale bar indicates with indicated cytosol, periplasm, and extracellular space. The scale bar indicates $50 \AA$. The inset table on the bottom summarize the thickness' values of the cell wall and its regions. The values in the inset table represent the mean of 40 independent tomograms. Related to Figure 5.

Supplementary Movie 1: Electron density map showing the features of the diffracting cell wall fraction with a detail of its main complexes. The T4P-like (orange), the SDBC (pink), and the dihedral complex (yellow) were extracted and refitted into the map. Related to Figure 3.

Supplementary Movie 2: Representative tomogram of a cell wall patch reconstructed from a typical specimen. Related to Figure 5.

\section{References}

Achouak W, Heulin T, Pagès JM. Multiple facets of bacterial porins. FEMS Microbiol Lett. 2001 May 15;199(1):1-7. doi: 10.1111/j.1574-6968.2001.tb10642.x. 
Bahl, H., Scholz, H., Bayan, N., Chami, M., Leblon, G., Gulik-Krzywicki, T., Shechter, E., Fouet, A., Mesnage, S., Tosi-Couture, E., Gounon, P., Mock, M., Conway de Macario, E., Macario, A.J., Fernández-Herrero, L.A., et al. (1997). Molecular biology of S-layers. FEMS Microbiol. Rev. 20, 47-98. doi: 10.1111/j.1574-6976.1997.tb00304.x.

Baumeister, W., Karrenberg, F., Rachel, R., Engel, A., ten Heggeler, B., Saxton, W.O. (1982). The major cell envelope protein of Micrococcus radiodurans (R1). Structural and chemical characterization. Eur. J. Biochem. 125, 535-544. doi: 10.1111/j.1432-1033.1982.tb06715.x.

Baumeister, W., Barth, M., Hegerl, R., Guckenberger, R., Hahn, M., Saxton, W.O. (1986). Threedimensional structure of the regular surface layer (HPI layer) of Deinococcus radiodurans. J. Mol. 405 Biol. 187, 241-250. doi: 10.1016/0022-2836(86)90231-7.

Beveridge, T.J., Pouwels, P.H., Sára, M., Kotiranta, A., Lounatmaa, K., Kari, K., Kerosuo, E., Haapasalo, M., Egelseer, E.M., Schocher, I., Sleytr, U.B., Morelli, L., Callegari, M.L., Nomellini, 10.1111/j.1574-6976.1997.tb00305.x. Focus: The interface between data collection and data processing in cryo-EM. J Struct Biol. 2017 May;198(2):124-133. doi: 10.1016/j.jsb.2017.03.007. 
Craig L, Forest KT, Maier B. Type IV pili: dynamics, biophysics and functional consequences. Nat Rev Microbiol. 2019 Jul;17(7):429-440. doi: 10.1038/s41579-019-0195-4.

Daly, M. A new perspective on radiation resistance based on Deinococcus radiodurans. Nat Rev Microbiol. 7, 237-245 (2009). doi: 10.1038/nrmicro2073.

Fagan RP, Fairweather NF. Biogenesis and functions of bacterial S-layers. Nat Rev Microbiol. 2014 Mar;12(3):211-22. doi: 10.1038/nrmicro3213.

Farci D, Bowler MW, Kirkpatrick J, McSweeney S, Tramontano E, Piano D. New features of the cell wall of the radio-resistant bacterium Deinococcus radiodurans. Biochim Biophys Acta. 2014 Jul;1838(7):1978-84. doi: 10.1016/j.bbamem.2014.02.014.

Farci D, Bowler MW, Esposito F, McSweeney S, Tramontano E, Piano D. Purification and characterization of DR_2577 (SlpA) a major S-layer protein from Deinococcus radiodurans. Front Microbiol. 2015 Jun 3;6:414. doi: 10.3389/fmicb.2015.00414.

Farci D, Slavov C, Tramontano E, Piano D. The S-layer Protein DR_2577 Binds Deinoxanthin and under Desiccation Conditions Protects against UV-Radiation in Deinococcus radiodurans. Front Microbiol. 2016 Feb 16;7:155. doi: 10.3389/fmicb.2016.00155.

Farci D, Farci SF, Esposito F, Tramontano E, Kirkpatrick J, Piano D. On the S-layer of Thermus thermophilus and the assembling of its main protein SlpA. Biochim Biophys Acta Biomembr. 2018a Aug;1860(8):1554-1562. doi: 10.1016/j.bbamem.2018.05.010.

Farci D, Slavov C, Piano D . Coexisting properties of thermostability and ultraviolet radiation resistance in the main S-layer complex of Deinococcus radiodurans. Photochem Photobiol Sci. 2018b Jan 17;17(1):81-88. doi: 10.1039/c7pp00240h.

Farci D, Guadalupi G, Bierła K, Lobinski R, Piano D. The Role of Iron and Copper on the Oligomerization Dynamics of DR_2577, the Main S-Layer Protein of Deinococcus radiodurans. Front Microbiol. 2019 Jun 28;10:1450. doi: 10.3389/fmicb.2019.01450. 
Farci D, Aksoyoglu MA, Farci SF, Bafna JA, Bodrenko I, Ceccarelli M, Kirkpatrick J, Winterhalter M, Kereïche S, Piano D. Structural insights into the main S-layer unit of Deinococcus radiodurans reveal a massive protein complex with porin-like features. J Biol Chem. 2020 Mar 27;295(13):4224-4236. doi: 10.1074/jbc.RA119.012174.

Farci D, Kereïche S, Pangeni S, Haniewicz P, Bodrenko IV, Ceccarelli M, Winterhalter M, Piano D. Structural analysis of the architecture and in situ localization of the main S-layer complex in Deinococcus radiodurans. Structure. 2021 Jul 12:S0969-2126(21)00249-5. doi: 10.1016/j.str.2021.06.014.

Gipson B, Zeng X, Zhang ZY, Stahlberg H. 2dx--user-friendly image processing for 2D crystals. J Struct Biol. 2007 Jan;157(1):64-72. doi: 10.1016/j.jsb.2006.07.020.

Gold V.A.M., Salzer Ralf, Averhoff Beate, Kühlbrandt W. Structure of the type IV pilus machinery in the open and closed state. elife. 2015 May 4:e07380. doi: 10.7554/eLife.07380.

Goodsell DS, Olson AJ, Forli S. Art and Science of the Cellular Mesoscale. Trends Biochem Sci. 2020 Jun;45(6):472-483. doi: 10.1016/j.tibs.2020.02.010.

Heumann JM, Hoenger A, Mastronarde DN. Clustering and variance maps for cryo-electron tomography using wedge-masked differences. J Struct Biol. 2011 Sep;175(3):288-99. doi: 10.1016/j.jsb.2011.05.011.

Kumar J, Ghosh P, Kumar A. (2021). Ultraviolet-B Radiation Stress-Induced Toxicity and Alterations in Proteome of Deinococcus radiodurans. Microb Physiol. 31, 1-15. doi: $10.1159 / 000512018$.

Lister TE, and Pinhero PJ. (2001). In vivo atomic force microscopy of sur- face proteins on Deinococcus radiodurans. Langmuir 17, 2624-2628. 
Mastronarde, D.N. (2005). Automated electron microscope tomography using robust prediction of specimen movements. J Struct Biol. 152, 36-51.

Messner, P., Allmaier, G., Schäffer, C., Wugeditsch, T., Lortal, S., König, H., Niemetz, R., Dorner, M. (1997). Biochemistry of S-layers. FEMS Microbiol. Rev. 20, 25- 46. doi: 10.1111/j.15746976.1997.tb00303.x.

Mindell JA, Grigorieff N. Accurate determination of local defocus and specimen tilt in electron microscopy. J Struct Biol. 2003 Jun;142(3):334-47. doi: 10.1016/s1047-8477(03)00069-8.

Müller, D.J., Baumeister, W., Engel, A. (1996). Conformational change of the hexagonally packed intermediate layer of Deinococcus radiodurans monitored by atomic force microscopy. $J$. Bacteriol. 178, 3025-303. doi: 10.1128/jb.178.11.3025-3030.1996.

Murray RGE. The Family Deinococcaceae A. Balows, H. G. T., H. Dworkin, W. Harder, K.H. Schleifer (Eds.), The Prokaryotes (2nd ed.), Springer, New York (1992), pp. 3732-3744.

Pavkov-Keller, T., Howorka, S., Keller, W. (2011). The structure of bacterial S-layer proteins. Prog. Mol. Biol. Transl. Sci. 103, 73-130. doi: 10.1016/B978-0-12-415906-8.00004-2.

Pettersen, E.F., Goddard, T.D., Huang, C.C., Couch, G.S., Greenblatt, D.M., Meng, E.C., Ferrin, T.E. (2004). UCSF Chimera--a visualization system for exploratory research and analysis. J Comput Chem. 25, 1605-12.

Pum D, Toca-Herrera JL, Sleytr UB. S-layer protein self-assembly. Int J Mol Sci. 2013 Jan 25;14(2):2484-501. doi: 10.3390/ijms14022484.

Rothfuss H, Lara JC, Schmid AK, Lidstrom ME. Involvement of the S-layer proteins Hpi and SlpA in the maintenance of cell envelope integrity in Deinococcus radiodurans R1. Microbiology (Reading). 2006 Sep;152(Pt 9):2779-2787. doi: 10.1099/mic.0.28971-0. 
Sleytr, U.B., Glauert, A.M. (1975). Analysis of regular arrays of subunits on bacterial surfaces: evidence for a dynamic process of assembly. J Ultrastruct Res. 50, 103-116. doi: 10.1016/s00225320(75)90012-x. across the outer membrane of Gram-negative bacteria. Nat Rev Microbiol. 2020 Mar;18(3):164176. doi: 10.1038/s41579-019-0294-2.

Yu J, Li T, Dai S, Weng Y, Li J, Li Q, Xu H, Hua Y, Tian B. A tamB homolog is involved in maintenance of cell envelope integrity and stress resistance of Deinococcus radiodurans. Sci Rep. 2017 Apr 6;7:45929. doi: 10.1038/srep45929.

Zheng SQ, Palovcak E, Armache JP, Verba KA, Cheng Y, Agard DA. MotionCor2: anisotropic correction of beam-induced motion for improved cryo-electron microscopy. Nat Methods. 2017 Apr;14(4):331-332. doi: 10.1038/nmeth.4193. 
Figure 1

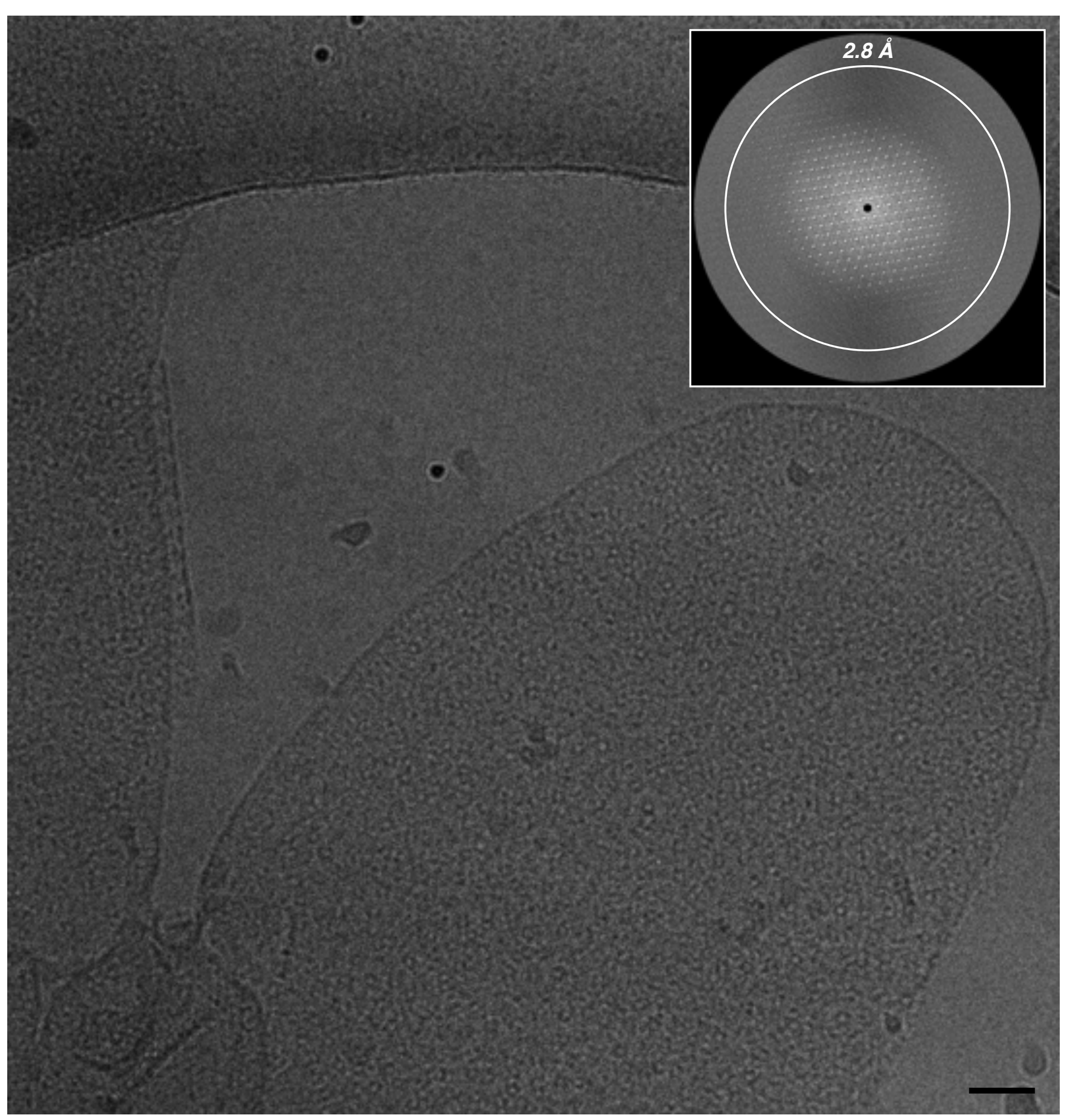


Figure 2

a)

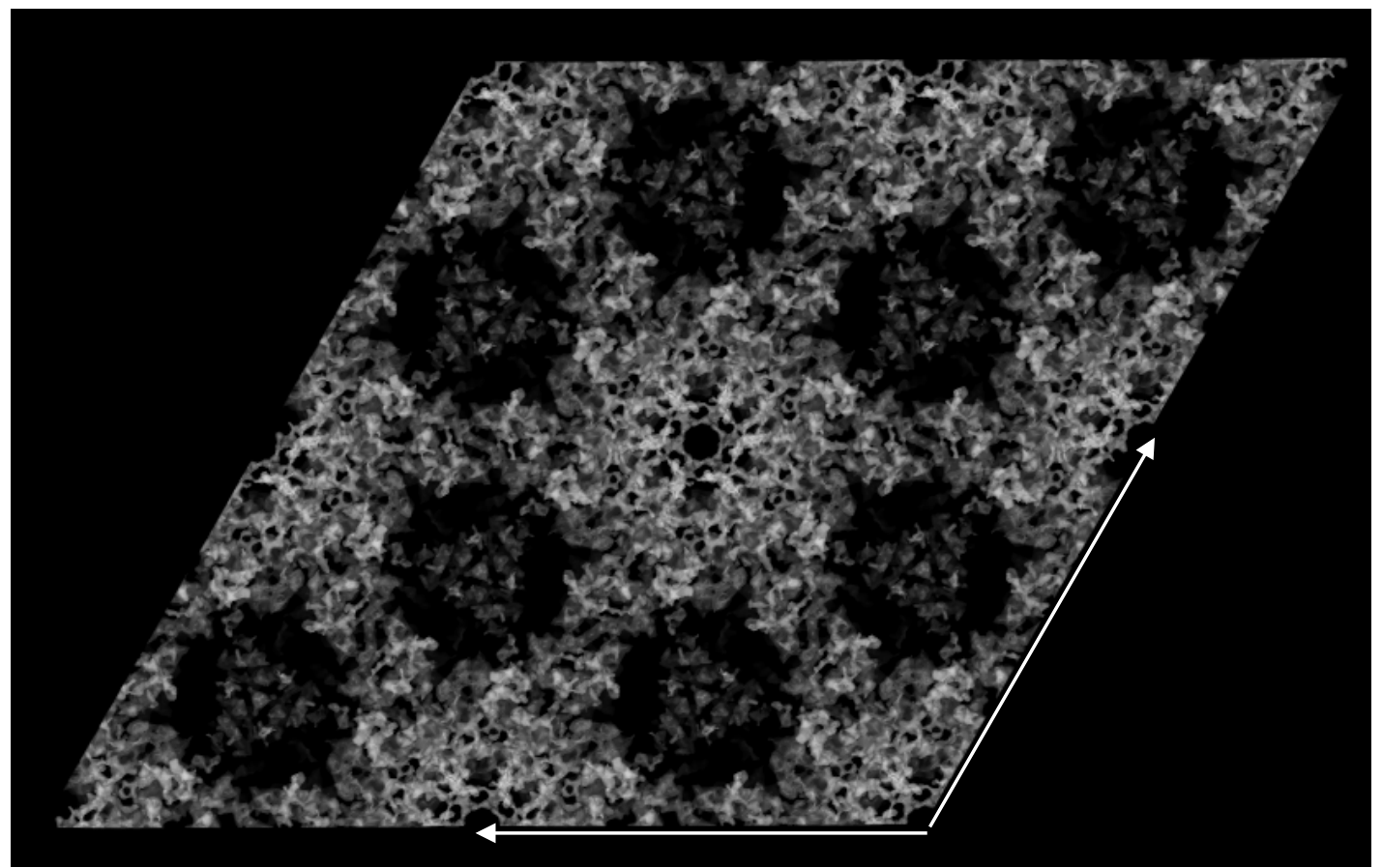

c)

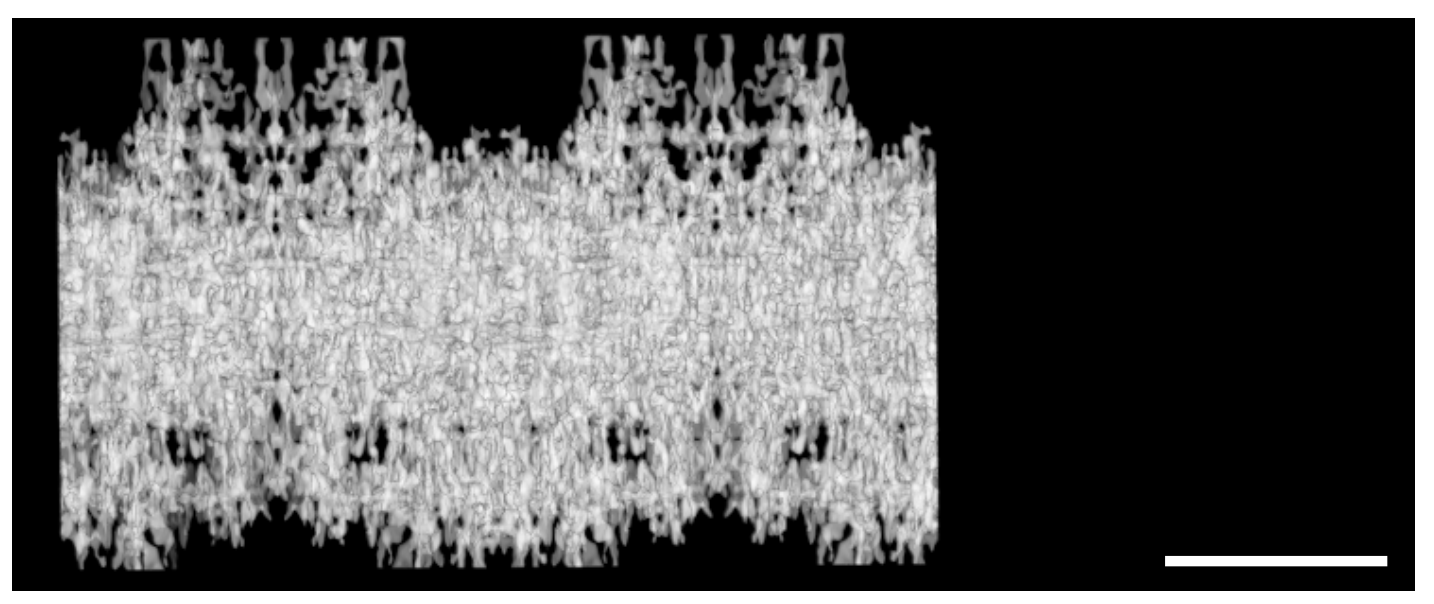

b)

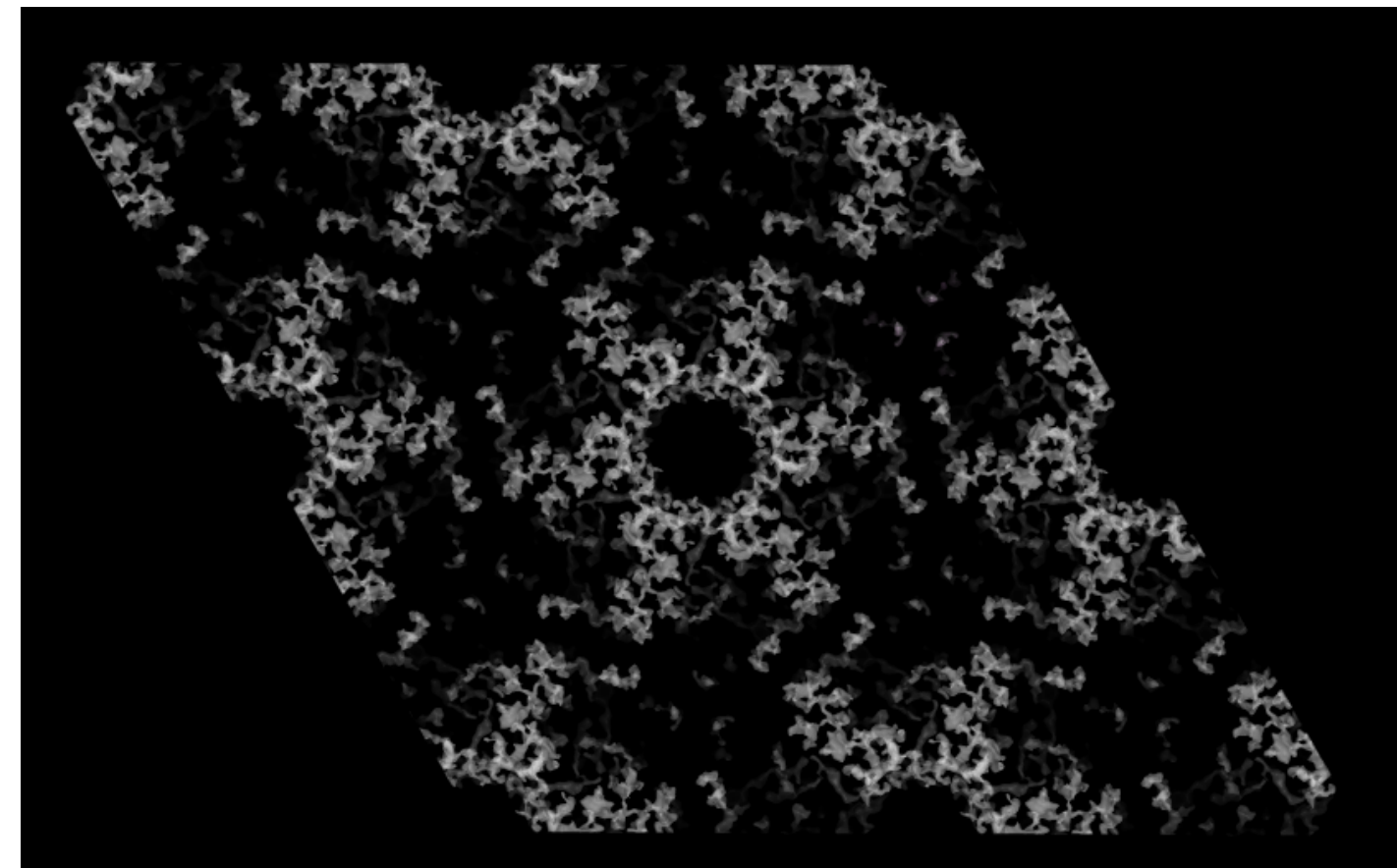

d)

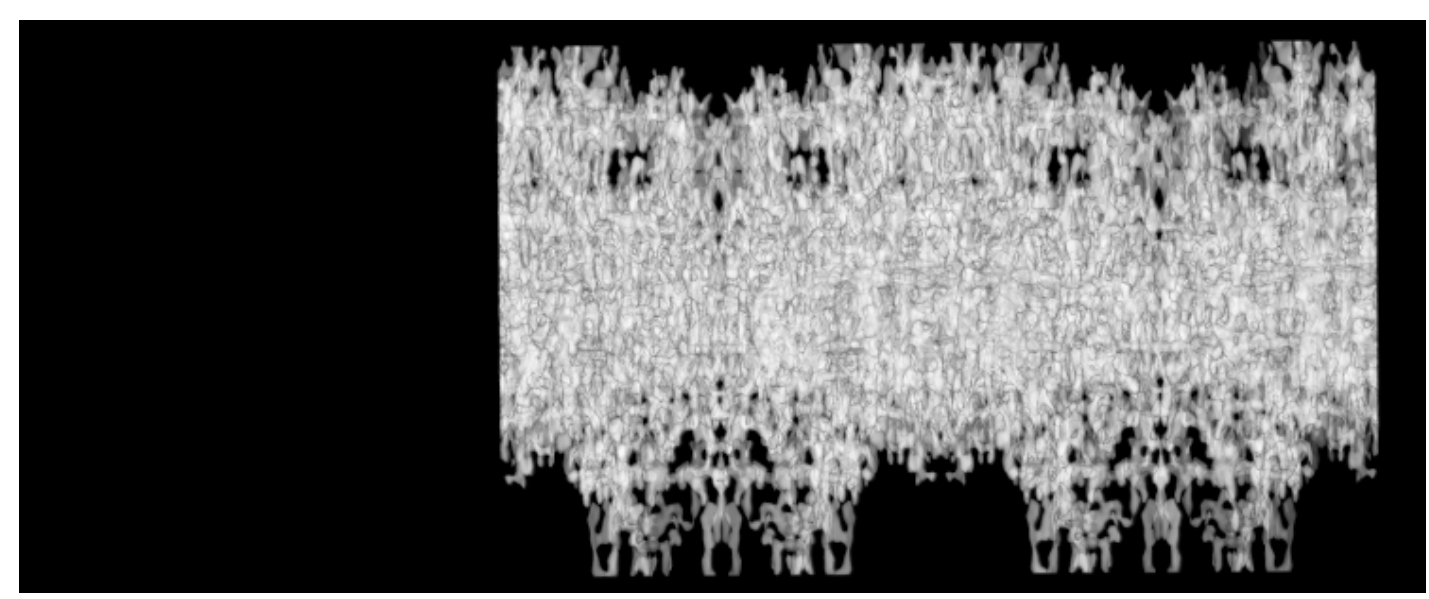




\section{Figure 3}
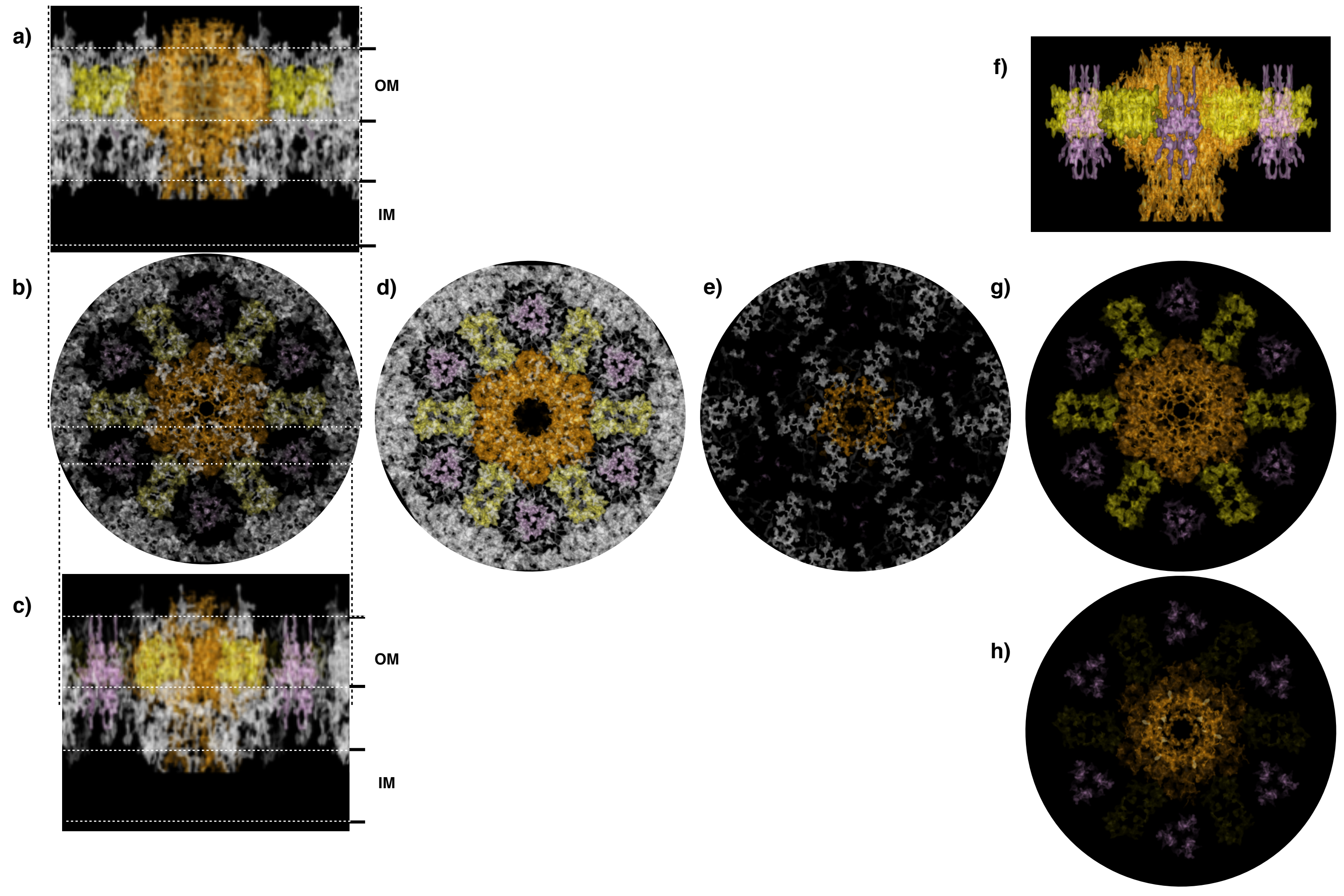

- $100 \AA$ 
Figure 4

a)

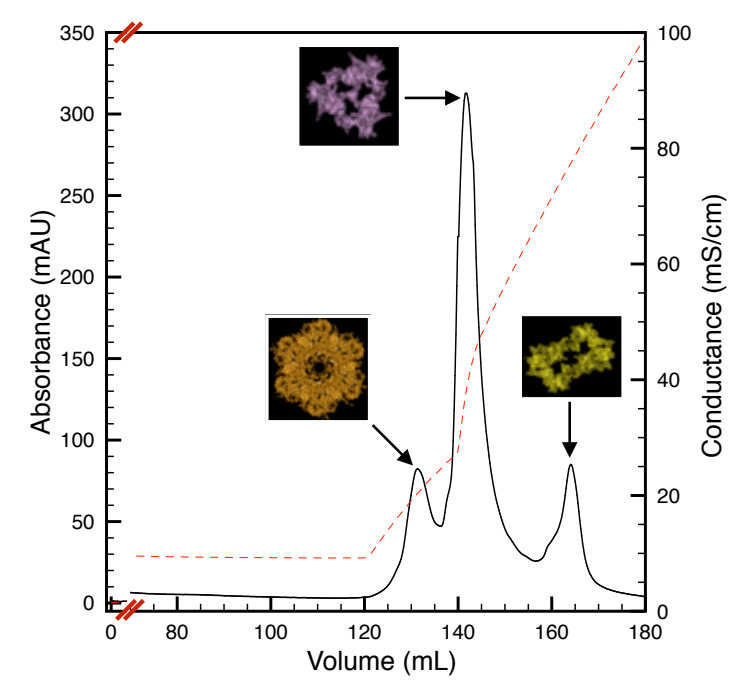

c)

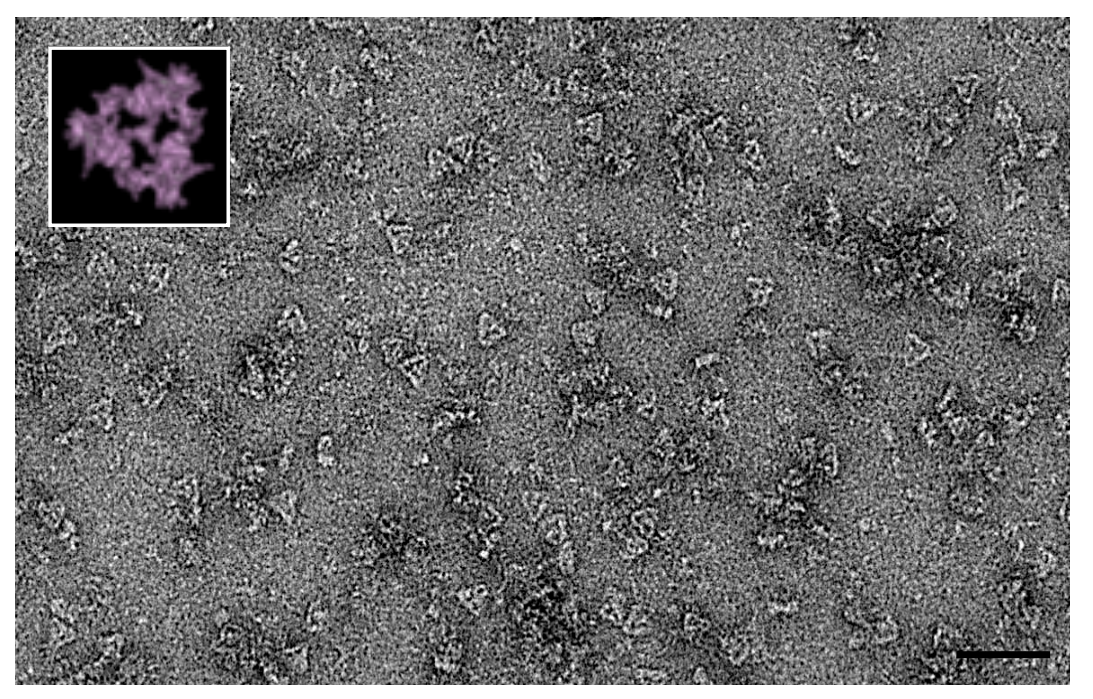

b)

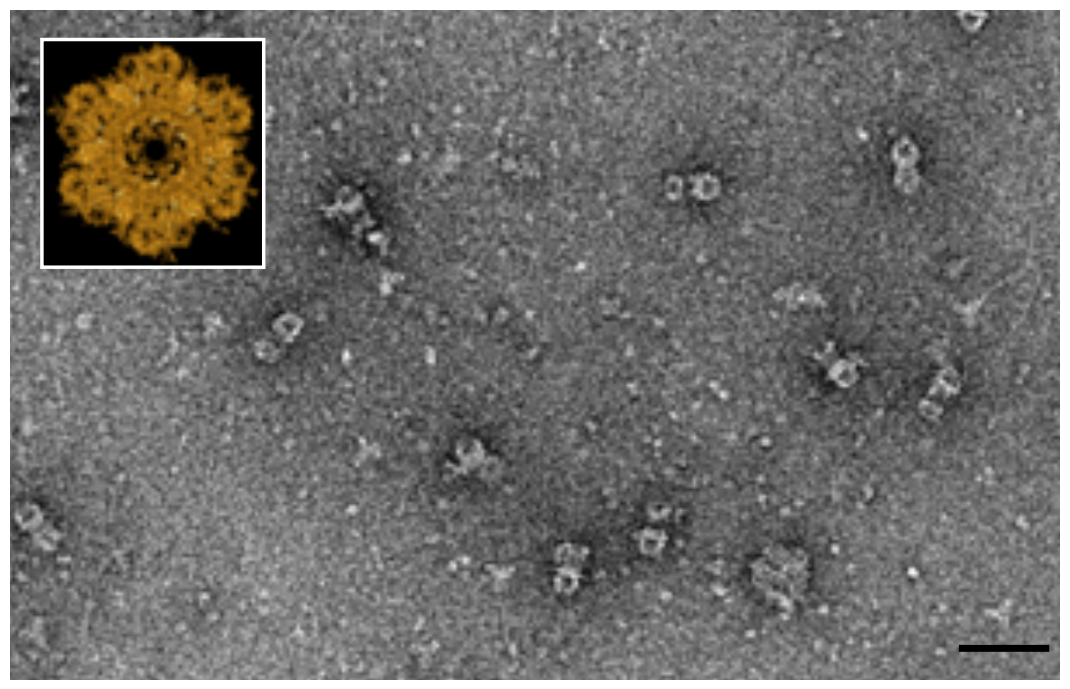

d)

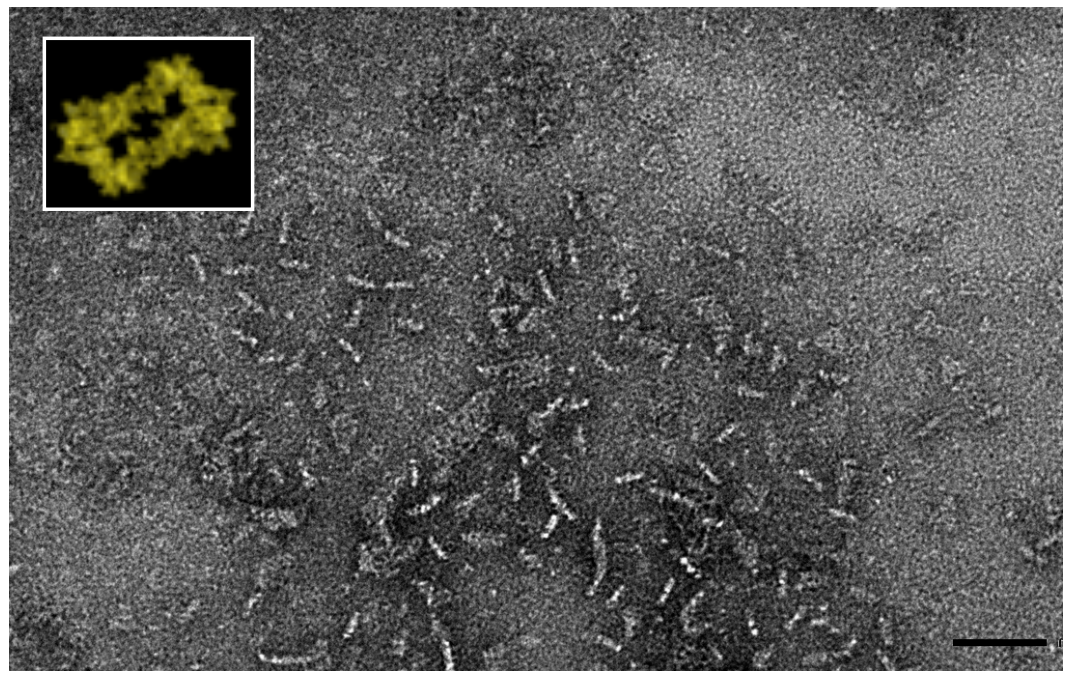


Figure 5

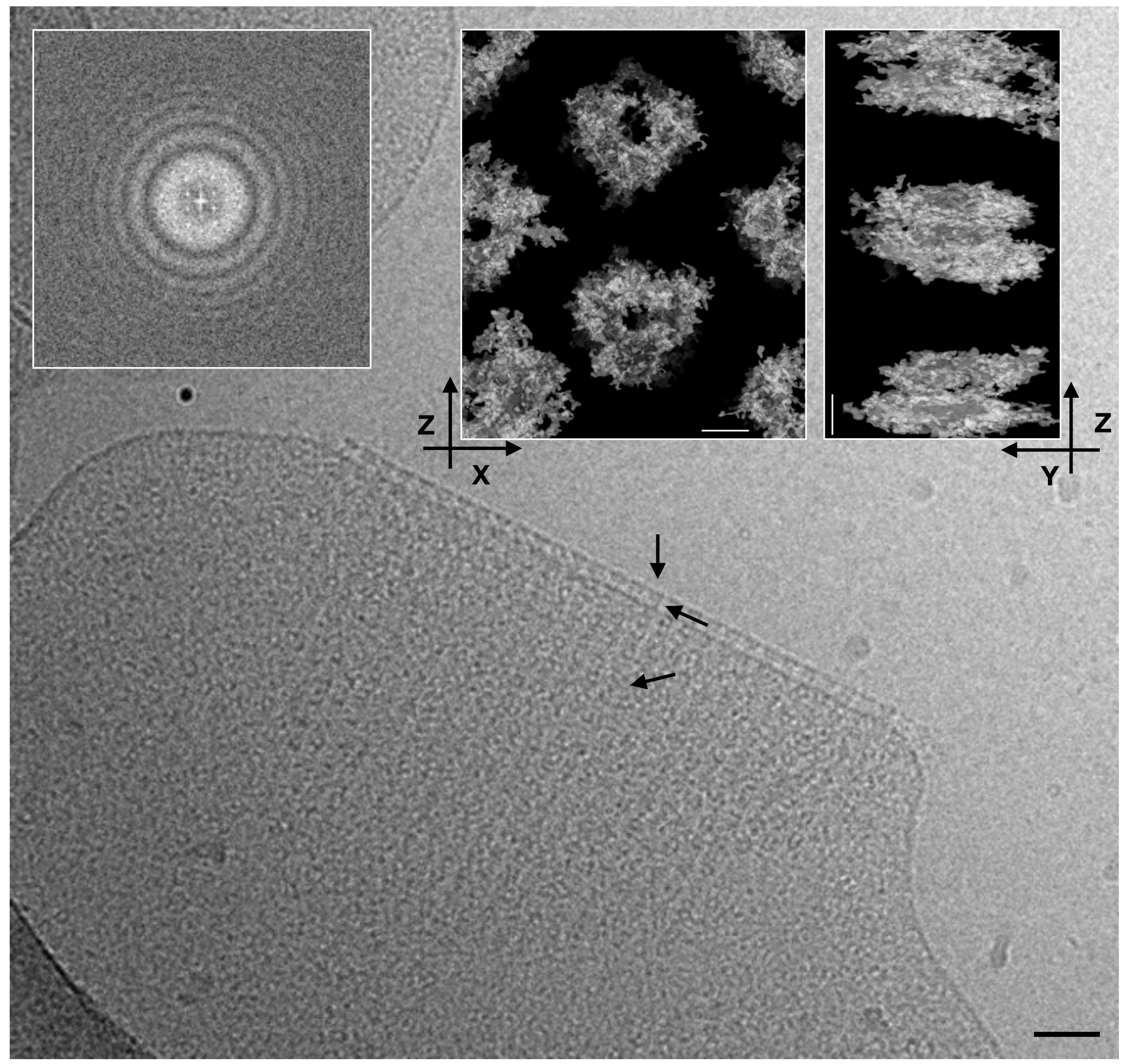


Figure 6

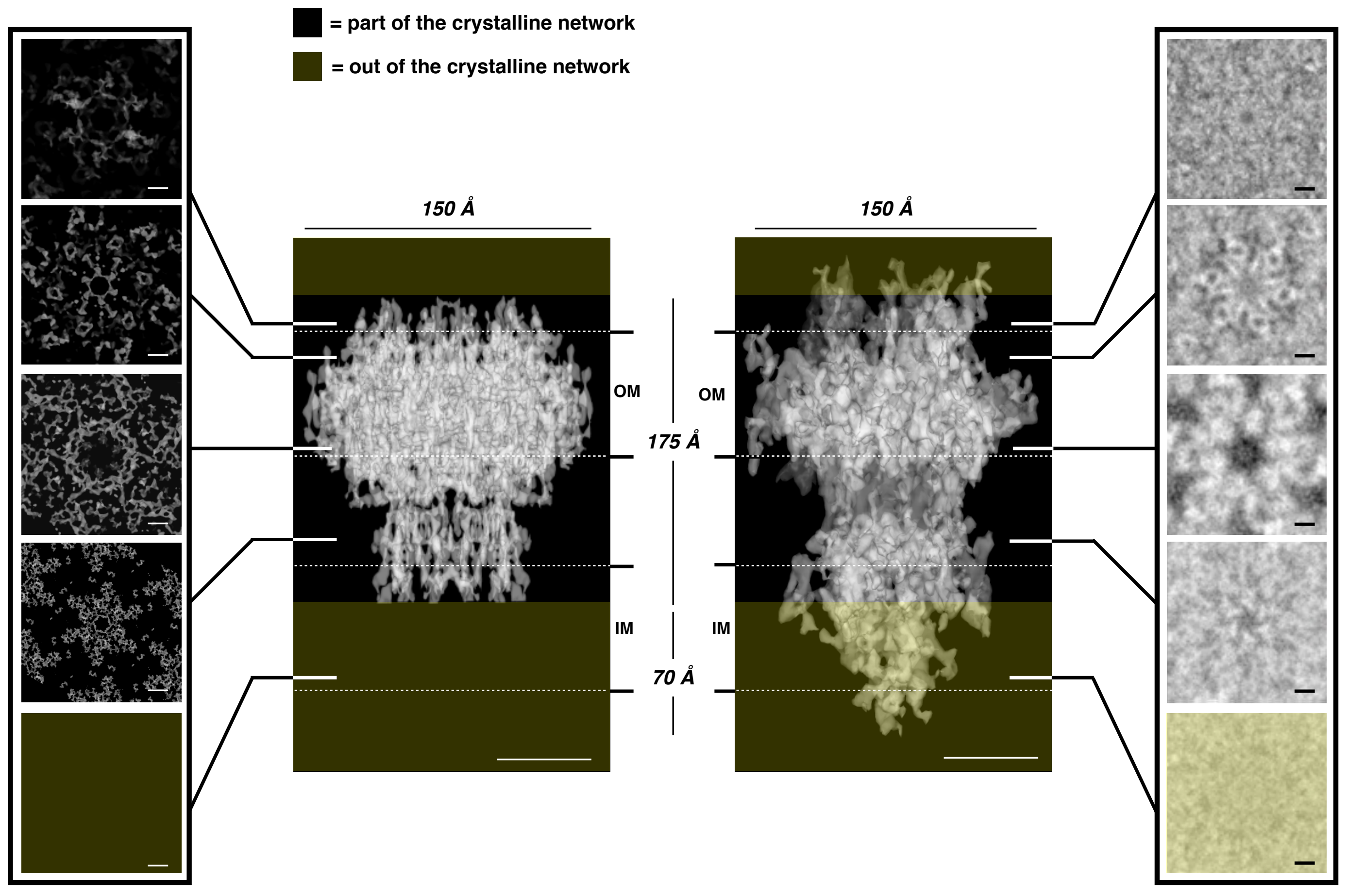




\section{Table 1}

Table 1 - Electron crystallographic parameters and data

\begin{tabular}{|c|c|c|}
\hline Plane group symmetry & \multicolumn{2}{|l|}{ p6 } \\
\hline Unit cell dimensions & \multicolumn{2}{|c|}{$\begin{array}{l}\mathrm{a}(\AA)=190 ; \mathrm{b}(\AA)=190 ; \mathrm{c}(\AA)=200 \\
\gamma\left(\left(^{\circ}\right)=120\right.\end{array}$} \\
\hline Number of images & \multicolumn{2}{|c|}{$\begin{array}{l}73 \\
\text { with tilt angle distribution: }\left[5\left(0^{\circ}\right) ; 6\left(+3^{\circ}\right) ; 3\left(-3^{\circ}\right) ; 4\left(+6^{\circ}\right) ; 5\left(-6^{\circ}\right) ; 4\left(+9^{\circ}\right) ; 4\left(-9^{\circ}\right) \text {; }\right. \\
4\left(+12^{\circ}\right) ; 4\left(-12^{\circ}\right) ; 2\left(+15^{\circ}\right) ; 1\left(-15^{\circ}\right) ; 2\left(+18^{\circ}\right) ; 2\left(-18^{\circ}\right) ; 2\left(+21^{\circ}\right) ; 2\left(-21^{\circ}\right) ; 2\left(+24^{\circ}\right) ; \\
3\left(-24^{\circ}\right) ; 2\left(+27^{\circ}\right) ; 2\left(-27^{\circ}\right) ; 2\left(+30^{\circ}\right) ; 2\left(-30^{\circ}\right) ; 1\left(+33^{\circ}\right) ; 1\left(-36^{\circ}\right) ; 2\left(+39^{\circ}\right) ; 1\left(-39^{\circ}\right) ; \\
\left.1\left(+42^{\circ}\right) ; 1\left(-42^{\circ}\right) ; 2\left(+45^{\circ}\right) ; 1\left(-45^{\circ}\right)\right]\end{array}$} \\
\hline Defocus range ( $\AA$ ) & \multicolumn{2}{|l|}{$39500-123738$} \\
\hline Magnification & \multicolumn{2}{|l|}{$21930 x$} \\
\hline Resolution in-plane (Å) & \multicolumn{2}{|l|}{4} \\
\hline Resolution in-z ( $\AA$ ) & \multicolumn{2}{|l|}{10} \\
\hline Number of observed unique reflections & \multicolumn{2}{|l|}{49905} \\
\hline Number of possible unique reflections & \multicolumn{2}{|l|}{25075} \\
\hline Overall phase error for 1000 spots $\left(^{\circ}\right)$ & \multicolumn{2}{|l|}{42.7} \\
\hline $\begin{array}{l}\text { Resolution }(\AA) \\
12.7 \\
8.9 \\
7.3 \\
6.3 \\
5.7 \\
5.2 \\
4.8 \\
4.5 \\
4.2 \\
4.0\end{array}$ & $\begin{array}{l}\text { Unique reflections }\left(\mathbf{N}^{\circ}\right)^{*} \\
102 \\
104 \\
101 \\
102 \\
104 \\
99 \\
104 \\
103 \\
96 \\
85\end{array}$ & $\begin{array}{l}\text { Phase residual }\left({ }^{\circ} * *\right. \\
24.9 \\
41.2 \\
41.4 \\
41.3 \\
47.9 \\
43.9 \\
47.1 \\
45.8 \\
52.3 \\
41.1\end{array}$ \\
\hline
\end{tabular}

* With $1 \leq \mathrm{IQ} \leq 6$ to $4.0 \AA$.

$* *$ Amplitude-weighted, vectorial averaged phase residuals that shows the phase deviation from theoretical $0^{\circ} / 180^{\circ}\left(45^{\circ}\right.$ is random). 